\title{
HUBUNGAN DUKUNGAN KELUARGA DENGAN KADAR GULA DARAH PADA PENYANDANG DIABETES MELITUS TIPE 2 DI PUSKESMAS BERINGIN RAYA KOTA BENGKULU
}

\author{
Desi Susanti ${ }^{1}$, Dita Amita ${ }^{2}$, Fourni Ardiansyah ${ }^{3}$ \\ 'Dosen Program Studi Keperawatan STIKes Bhakti Husada Bengkulu \\ Email : desidarul52@gmail.com \\ ${ }^{2}$ Dosen Program Studi Keperawatan STIKes Bhakti Husada Bengkulu \\ Email : ditaamita.da@gmail.com \\ ${ }^{3}$ Dosen Program Studi Keperawatan STIKes Bhakti Husada Bengkulu \\ Email : fourni.ardiansyahmaliki@gmail.com
}

\section{ABSTRACT : RELATIONSHIP OF FAMILY SUPPORT WITH BLOOD SUGAR LEVELS IN DIABETES MELITUS TYPE 2 PATIENTS IN PUBLIC HEALTH CENTER BERINGIN RAYA AT BENGKULU CITY}

Background : Implementation of controlling blood sugar levels to remain stable in a person with type 2 Diabetes Mellitus needs the support of the closest person, namely the family. Families can help to arrange physical activity schedules and help process food for diets for diabetes.

Purpose: to provide an overview, information, knowledge, and insight on family support for blood sugar levels in type 2 diabetes mellitus clients and can be used as material for study and information in developing nursing knowledge in providing nursing care for type 2 diabetes mellitus clients.

Methods: This research was a descriptive quantitative study with cross sectional approach to see family support in patients with type 2 diabetes mellitus. Samples in this study were 30 patients with a sampling technique using purposive sampling method.

Result: There was a significant relationship between family support and blood sugar levels of people with type 2 diabetes ( $p$ value $=0.002$ )

Conclusion: Family support for people with type 2 diabetes in this study was mostly in the good category (63.3\%), controlled blood sugar levels were more dominated than uncontrolled (56.7\%). There is a significant relationship between family support and blood sugar levels of people with type 2 diabetes mellitus.

Keywords: Family Support; Blood Glucose; Diabetes Mellitus

Desi Susanti ${ }^{1}$, Dita Amita ${ }^{2}$, Fourni Ardiansyah ${ }^{3}$

${ }^{1}$ Program Studi Keperawatan STIKes Bhakti Husada Bengkulu. Email: desidarul52@gmail.com

${ }^{2}$ Program Studi Keperawatan STIKes Bhakti Husada Bengkulu. Email: ditaamita.da@gmail.com

${ }^{3}$ Program Studi Keperawatan STIKes Bhakti Husada Bengkulu. Email :

fourni.ardiansyahmaliki@gmail.com 


\section{INTISARI : HUBUNGAN DUKUNGAN KELUARGA DENGAN KADAR GULA DARAH PADA PENYANDANG DIABETES MELITUS TIPE 2 DI PUSKESMAS BERINGIN RAYA KOTA BENGKULU}

Pendahuluan: Pelaksanaan mengontrol kadar gula darah agar tetap stabil pada seorang penyandang Diabetes Melitus tipe 2 perlu adanya dukungan dari orang terdekat,yaitu keluarga. Keluarga dapat membantu untuk mengatur jadwal aktifitas fisik dan membantu mengolah makanan untuk diet untuk diabetes.

Tujuan: untuk memberikan gambaran, informasi, pengetahuan, serta wawasan tentang dukungan keluarga terhadap kadar gula darah pada klien diabetes melitus tipe 2 dan Dapat dijadikan sebagai bahan kajian dan informasi dalam mengembangkan ilmu keperawatan dalam memberikan asuhan keperawatan terhadap klien diabetes melitus tipe 2.

Metode: Penelitian ini merupakan penelitian kuantitatif deskriptif dengan pendekatan cross sectional untuk melihat dukungan keluarga pada pasien diabetes mellitus tipe 2. Sampel dalam penelitian ini berjumlah 30 pasien dengan teknik pengambilan sampel menggunakan metode purposive sampling. Hasil Penelitian: ada hubungan yang signifikan antara dukungan keluarga dengan kadar gula darah penyandang DM tipe 2 ( $p$ value $=0,002$ )

Kesimpulan : Dukungan keluarga pada penyandang DM tipe 2 pada penelitian ini sebagian besar pada kategori baik $(63,3 \%)$, kadar gula darah terkontrol lebih didominasi disbanding yang tidak terkontrol (56,7\%). Ada hubungan yang signifikan antara dukungan keluarga dengan kadar gula darah penyandang Diabetes Melitus tipe 2.

Kata Kunci : Dukungan Keluarga; Gula Darah; Diabetes Mellitus

\section{PENDAHULUAN}

WHO (2020) melaporkan bahwa jumlah penderita diabetes meningkat dari 108 juta pada 1980 menjadi 422 juta pada 2014. Pada 2016, diperkirakan 1,6 juta kematian secara langsung disebabkan oleh diabetes kemudian 2,2 juta kematian lainnya disebabkan oleh glukosa darah tinggi pada tahun 2012. Hampir setengah dari semua kematian yang disebabkan oleh glukosa darah tinggi terjadi sebelum usia 70 tahun. WHO memperkirakan bahwa diabetes adalah penyebab utama ketujuh kematian pada tahun 2016.

\begin{abstract}
Situasi di Indonesia berdasarkan dari hasil Riset Kesehatan Dasar (Rsiskesdas) pada tahun 2018 menjelaskan prevalensi DM berdasarkan usia $\geq 15$ tahun 2018 meningkat menjadi 2\% dibandingkan dengan data tahun 2013 lalu. Prevalensi DM berdasarkan diagnosis dokter dan usia $\geq 15$ tahun yang terendah terdapat di Provinsi NTT, yaitu sebesar $0,9 \%$, sedangkan prevalensi DM tertinggi di Provinsi DKI Jakarta sebesar 3,4\% (Kemenkes, 2018). Diabetes dapat dikontrol dengan menjaga kadar gula darah stabil dan kadar normal dengan
\end{abstract}

Desi Susanti ${ }^{1}$, Dita Amita ${ }^{2}$, Fourni Ardiansyah ${ }^{3}$

${ }^{1}$ Program Studi Keperawatan STIKes Bhakti Husada Bengkulu. Email: desidarul52@gmail.com

${ }^{2}$ Program Studi Keperawatan STIKes Bhakti Husada Bengkulu. Email: ditaamita.da@gmail.com

${ }^{3}$ Program Studi Keperawatan STIKes Bhakti Husada Bengkulu. Email :

fourni.ardiansyahmaliki@gmail.com 
melakukan diet, aktivitas fisik, pengobatan dan skrining serta pengobatan rutin agar tidak terjadi komplikasi. Pola makan yang sehat, aktivitas fisik yang teratur, mempertahankan berat badan yang normal dan menghindari penggunaan tembakau adalah cara untuk mencegah atau menunda timbulnya diabetes tipe 2 (Rahman, 2015).

Pelaksanaan mengontrol kadar gula darah agar tetap stabil pada seorang penyandang Diabetes Melitus tipe 2 perlu adanya dukungan dari orang terdekat,yaitu keluarga. Keluarga dapat membantu untuk mengatur jadwal aktifitas fisik dan membantu mengolah makanan untuk diet untuk diabetes. Gula darah yang dikontrol sebelum dan sesudah makan berguna untuk melihat pengaruh dari hasil diet, olahraga dan pengobatan lain yang pernah dilakukan. Menjaga kestabilan tekanan darah dan menjalankan gaya hidup sehat dapat mencegah dari risiko komplikasi diabetes mellitus (Sutanto, 2010). Hasil penelitian yang dilakukan oleh Yanto dan Dewi (2017) yang dilkukan di kota Semarang menyimpulkan dukungan keluarga yang baik akan mempengaruhi pelaksanaan program pengobatan diabetes mellitus yang dijalani oleh pasien Diabetes Melitus. Hasil yng ditemukan pada penelitian mereka yaitu dukungan keluarga pada pasien diabetes mellitus tipe $2 \mathrm{di}$ kota Semarang lebih didominasi oleh kategori baik atau dukungan keluarga tinggi yaitu sebesar $72,9 \%$ dari total responden.
Penelitian Wardani dan Muhammad (2014) dengan judul "Family Support and Glucose Control Related to Microvascular Complications Symptoms" menyimpulkan hasil penelitiannya bahwa ada penyandang Diabetes mellitus cukup mendapatkan dukungan dari keluarganya, kemudian ditemukan setengah dari jumlah penyandang Diabetes mellitus yang menjadi responden melakukan pengendalian kadar gula darah dengan baik. Dukungan keluarga yang baik dapat membuat responden melakukan pengendalian kadar gula darah dengan baik.

Beberapa hasil penelitian di atas menunjukkan bahwa dukungan keluarga sangat berperan penting untuk memotivasi penyandang Diabetes Melitus dalam melakukan kegiatan diet, aktifitas fisik yang teratur, dan mengkonsumsi obat.. Adapun pentingnya penelitian ini dilakukan adalah untuk memberikan gambaran, informasi, pengetahuan, serta wawasan tentang dukungan keluarga terhadap kadar gula darah pada klien diabetes melitus tipe 2 dan Dapat dijadikan sebagai bahan kajian dan informasi dalam mengembangkan ilmu keperawatan dalam memberikan asuhan keperawatan terhadap klien diabetes melitus tipe 2 .

\section{METODE}

Penelitian ini merupakan penelitian kuantitatif deskriptif dengan pendekatan cross sectional untuk melihat dukungan keluarga pada pasien diabetes mellitus tipe 2. Sampel dalam penelitian ini

Desi Susanti ${ }^{1}$, Dita Amita ${ }^{2}$, Fourni Ardiansyah ${ }^{3}$

${ }^{1}$ Program Studi Keperawatan STIKes Bhakti Husada Bengkulu. Email: desidarul52@gmail.com

${ }^{2}$ Program Studi Keperawatan STIKes Bhakti Husada Bengkulu. Email: ditaamita.da@gmail.com

${ }^{3}$ Program Studi Keperawatan STIKes Bhakti Husada Bengkulu. Email :

fourni.ardiansyahmaliki@gmail.com 
berjumlah 30 pasien diabetes mellitus tipe 2 diPuskesmas Beringin Raya Kota Bengkulu. Instrumen penelitian pada dukungan keluarga menggunakan Hensarling Diabetes Family Support Scale (HDFSS) yang terdiri atas 29 pertanyaan dengan alternatif jawaban $4=$ selalu, $3=$ sering, $2=$ jarang, $1=$ tidak pernah. Instrument ini sudah valid dengan nilai validitas 0,5 dan nilai reabilitas adalah Alpha Cronbach adalah 0,96 dan pernah digunakan oleh Yusra (2011), kemudian melakukan observasi catatan riwayat pasien hasil pemeriksaan kadar gula darah pasien.

Teknik pengambilan sampel menggunakan metode non probability sampling dengan pendekatan purposive sampling dengan jumlah sampel 30 orang. Adapun kriteria inklusi yaitu klien yang terdiagnosa diabetes melitus tipe 2 di Puskesmas Beringin Raya Kota Bengkulu, pasien yang bersedia menjadi responden, pasien bisa menulis dan membaca,dan lama terdiagnosa diabetes 1-5 tahun. Pengolahan analisis data menggunakan aplikasi SPSS 16.

HASIL

Tabel 1. Karakteristik pasien DM tipe 2 berdasarkan usia

\begin{tabular}{ccccc}
\hline Variabel & Mean & SD & Min-mak & $95 \% \mathrm{Cl}$ \\
\hline Usia & 56,53 & 3,57 & $49-62$ & $55,20-57,87$ \\
\hline
\end{tabular}

Berdasarkan tabel 1 diatas diketahui bahwa rata-rata usia responden adalah 56,53 tahun dengan standar deviasi 3,57 tahun, usia termuda 49 tahun dan tertua 62 tahun.

Tabel 2. Karakteristik pasien DM tipe 2 berdasarkan jenis kelamin

\begin{tabular}{lcc}
\hline \multicolumn{1}{c}{ Jenis Kelamin } & $\mathbf{n}$ & $\%$ \\
\hline Perempuan & 24 & 72,7 \\
Laki-laki & 6 & 18,2 \\
\hline Jumlah & 30 & 100 \\
\hline
\end{tabular}

Berdasarkan tabel 2 diatas diketahui bahwa karakteristik responden berdasarkan jenis kelamin terlihat proporsi perempuan lebih besar disbanding dengan laki-laki yaitu sebesar

Tabel 3. Hasil Analisis Univariat

\begin{tabular}{lcc}
\hline Variabel & $\mathbf{n}$ & $\%$ \\
\hline Dukungan Keluarga & & \\
Baik & 19 & 63,3 \\
Kurang Baik & 11 & 36,7 \\
\hline Kadar Gula Darah & & \\
Terkontrol & 17 & 56,7 \\
Tidak terkontrol & 13 & 43,3 \\
\hline
\end{tabular}

Desi Susanti ${ }^{1}$, Dita Amita ${ }^{2}$, Fourni Ardiansyah ${ }^{3}$

${ }^{1}$ Program Studi Keperawatan STIKes Bhakti Husada Bengkulu. Email: desidarul52@gmail.com ${ }^{2}$ Program Studi Keperawatan STIKes Bhakti Husada Bengkulu. Email: ditaamita.da@gmail.com ${ }^{3}$ Program Studi Keperawatan STIKes Bhakti Husada Bengkulu. Email :

fourni.ardiansyahmaliki@gmail.com 
Pada table 3. menunjukkan hasil dari analisis univariat, sebagian besar $(63,3 \%)$ dukungan keluarga baik pada respon Dm tipe 2, sedangkan pada kadar gula darah penyandang DM lebih dari setengah $(56,7 \%)$ dapat menjaga gula darah tetap terkontrol.

Tabel 4. Hasil analisis Bivariat

\begin{tabular}{|c|c|c|c|c|c|}
\hline \multirow{3}{*}{$\begin{array}{c}\text { Dukungan } \\
\text { Keluarga }\end{array}$} & \multicolumn{4}{|c|}{ Kadar Gula Darah } & \multirow[b]{2}{*}{$P$ value } \\
\hline & \multicolumn{2}{|c|}{ Terkontrol } & \multicolumn{2}{|c|}{ Tidak Terkontrol } & \\
\hline & $n$ & $\%$ & $\mathbf{n}$ & $\%$ & \multirow{3}{*}{0,002} \\
\hline Baik & 15 & 78,9 & 4 & 21,1 & \\
\hline Kurang Baik & 2 & 18,2 & 9 & 81,8 & \\
\hline
\end{tabular}

Pada table 4. Dari hasil analisis antara dukungan keluarga dengan kadar gula darah penyandang Dm tipe 2 diperoleh sebanyak 4 $(21,1 \%)$ orang dukungan keluarga yang baik namun mengalami kadar gula darah yang tidak terkontrol,sedangkan diantara dukungan keluarga yang kurang baik ada $9(81,8 \%)$ orang yang mengalami kadar gula darah yang tidak terkontrol.

\section{PEMBAHASAN}

Hasil penelitian yang
ditemukan peneliti dalam
dukungan keluarga yang kurang baik tersebut dikarenakan ada beberapa faktor, seperti terdapat keluarga yang hanya tinggal sendiri dirumah, sehingga susah untuk mengedalikan diet, kemudian masih ditemukan keluarga yang kurang memperhatikan jadwal kontrol berobat juga berolahraga yang sudah disediakan jadwal senam di puskesmas Beringin Raya.

Hasil kadar gula darah penyandang diabetes mellitus tipe 2 yang tidak terkontrol ditemukan sebesar 43,3\%. Dari hasil wawancara peneliti pada responden dan petugas kesehatan di puskesmas Beringin Raya,
Hasil uji statistic didapatkan nilai $P$ value $=0,002$, maka dapat disimpulkan ada perbedaan proporsi kejadian kadar gula darah yang tidak terkontrol antara dukungan keluarga yang kurang baik dengan yang baik, dengan kata lain ada hubungan yang signifikan antara dukungan keluarga dengan kadar gula darah penyandang DM tipe 2.

diperoleh pasien sering tidak teratur datang kontrol ke pelayanan kesehatan yang sudah disediakan, pasien juga sering tidak teratur dalam mengkonsumsi obat Diabetes. Selain itu, dirumah beberapa pasien sulit untuk melaksanakan diet sesuai anjuran dari petugas kesehatan berikan.

Hasil analisis bivariate antara dukungan keluarga dengan kadar gula darah diperoleh $p$ value 0.002 yang berarti ada hubungan yang sangat signifikan antara dukungan keluarga dengan kadar gula darah penyandang DM tipe 2 . Semakin baik dukungan keluarga berikan pada perawatan penyandang DM, maka kadar gula darah pasien akan terkontrol dengan baik. Sejalan dengan hasil

Desi Susanti ${ }^{1}$, Dita Amita ${ }^{2}$, Fourni Ardiansyah ${ }^{3}$

${ }^{1}$ Program Studi Keperawatan STIKes Bhakti Husada Bengkulu. Email: desidarul52@gmail.com

${ }^{2}$ Program Studi Keperawatan STIKes Bhakti Husada Bengkulu. Email: ditaamita.da@gmail.com

${ }^{3}$ Program Studi Keperawatan STIKes Bhakti Husada Bengkulu. Email :

fourni.ardiansyahmaliki@gmail.com 
penelitian Nuraisyah,dkk (2017) bahwa dukungan keluarga yang baik dapat mempengaruhi kualitas hidup pasien DM tipe 2 .

Senuk,et.al

menyatakan hasil penelitiannya bahwa dukungan keluarga juga berhubungan dengan kepatuhan pasien dalam menjalani diet diabetes mellitus, kemudian Setyawaty (2013) juga menyatakan bahwa dukungan keluarga dapat menurunkan stress pasien pada penyakit.

Peneliti menegaskan hasil penelitian yang ditemukan serta memahami hasil penelitian peneliti lain sebelumnya, bahwa peran dukungan keluarga pada penyandang DM sangat penting dan luas, jika keluarga tidak menganggapi secara serius dalam merawat salah satu anggota keluarganya yang sakit, maka akan sangat berpengaruh terhadap keadaan kesehatan dan berpengaruh secara jangka panjang pada kualitas hidup pasien DM.

\section{KESIMPULAN \\ Dukungan keluarga pada penyandang DM tipe 2 pada penelitian ini sebagian besar pada kategori baik $(63,3 \%)$, kadar gula darah terkontrol () lebih didominasi disbanding yang tidak terkontrol (56,7\%). Ada hubungan yang signifikan antara dukungan keluarga dengan kadar gula darah penyandang Diabetes Melitus tipe 2.}

\section{SARAN}

Perlu untuk dikembangkan kompetensi perawat dalam memberdayakan keluarga dalam perawatan pasien DM dirumah.

\section{DAFTAR PUSTAKA}

Kementrian Kesehatan RI . (2018). Pusat Data dan Informasi Kementrian Kesehatan RI. Pusdatin.kemkes.go.id

Nuraisyah, Fatma, et al. (2017). Family support and quality of life among patients with diabetes melitus. Journal of Community Medicine and public Health, Vol 33 No 01 Tahun 2017.

Rahman, U, M. (2015). Hubungan kepatuhan dalam menjalankan diet dengan pengendalian kadar gula darah pada pasien diabetes melitus di puskesmas global limboto. Diunduh di http://eprints.ung.ac.id/1228 9/1/2014-1-1-14201841410107-abstraksi19082014093811.pdf.

Senuk, A., Supit, W. \& Onibala, F. (2013). Hubungan Pengetahuan dan Dukungan Keluarga dengan Kepatuhan Menjalani Diet Diabetes Melitus di Poliklinik RSUD Kota Tidore Kepulauan Provinsi Maluku Utara. JURNAL KEPERAWATAN, 1.

Setiati, Siti., Alwi, Idrus,. Sudoyo, Aru, W., Simadibrata K, Marcellus., Setiyohadi, Bambang., \& syam, A, F. (2014). Buku ajar ilmu penyakit dalam jilid ii $\left(6^{\text {th }}\right.$ ed). Jakarta: Interna publishing.

Sugandha dkk. (2014). Gambaran pengendalian kadar gula darah dan HbAlc pada pasien

Desi Susanti ${ }^{1}$, Dita Amita ${ }^{2}$, Fourni Ardiansyah ${ }^{3}$

${ }^{1}$ Program Studi Keperawatan STIKes Bhakti Husada Bengkulu. Email: desidarul52@gmail.com

${ }^{2}$ Program Studi Keperawatan STIKes Bhakti Husada Bengkulu. Email: ditaamita.da@gmail.com

${ }^{3}$ Program Studi Keperawatan STIKes Bhakti Husada Bengkulu. Email :

fourni.ardiansyahmaliki@gmail.com 
diabetes melitus tipe 2 yang di rawat di RSUP Sanglah.

Sutanto. (2010). Cekal (Cegah dan Tangkal) Penyakit Modern (Hipertensi, Stroke, Jantung, Kolesterol, dan Diabetes). Yogyakarta : Andi Yogyakarta.

Wardani dan Muhammad. (2014). Family Support and Glucose Control Related to Microvascular Complications Symptoms. Jurnal Berkala Epidemiologi, Volume 2 Nomor 1, Januari 2014.

Worlth Health Oragnization (WHO). (2020). Diabetes, Key fact. https://www. who.int/newsroom/factsheets/detail/diabetes diakses pada 8 Juni 2020.

Yanto dan Dewi .(2017). Dukungan

Keluarga Pada Pasien Diabetes Mellitus Tipe $2 \mathrm{Di}$ Kota Semarang. Prosiding Seminar Nasional Publikasi Hasil-Hasil Penelitian dan Pengabdian Masyarakat; Implementasi Penelitian dan Pengabdian Masyarakat Untuk Peningkatan Kekayaan Intelektual. Universitas Muhammadiyah Semarang.

Yusra, A. (2011). Hubungan antara dukungan keluarga dengan kualitas hidup pasien diabetes melitus tipe 2 dipoliklinik penyakit dalam Rumah Sakit umum pusat Fatmawati .Jakarta Utara. FKUI 